\title{
Erratum to: Photometric sandwich immunoassay for Salmonella pullorum and Salmonella gallinarum using horseradish peroxidase and magnetic silica nanoparticles
}

\author{
Haitao Zhu ${ }^{1}$ - Guangying Zhao ${ }^{1} \cdot$ Su Qiang Wang ${ }^{1} \cdot$ Wenchao Dou $^{1}$
}

Published online: 26 April 2017

(C) Springer-Verlag Wien 2017

Erratum to: Microchimica Acta

DOI 10.1007/s00604-017-2241-0

The original version of this article, unfortunately, contained error in Table 1. Given in this article is the correct table.

Table 1 A comparison of the analytical characteristics of the immunosensor developed in this work with relevant

immunosensors and aptasensor for pathogensa

\begin{tabular}{llll}
\hline Methods & Linearity range $\left(\mathrm{CFU} \mathrm{mL}{ }^{-1}\right)$ & LOD $\left.(\mathrm{CFU} \mathrm{mL})^{-1}\right)$ & Ref. \\
\hline Fluorescence & $10^{5}-10^{7}$ & 10 & {$[13]$} \\
Absorbance & $2.2 \times 10^{4}-2.2 \times 10^{6}$ & $2.0 \times 10^{4}$ & {$[14]$} \\
BioFETs & not mentioned & $1.9 \times 10^{5}$ & {$[15]$} \\
Amperometry & $10^{2}-10^{6}$ & 89 & {$[16]$} \\
CGM & $1.2 \times 10^{5}-1.2 \times 10^{8}$ & $1.0 \times 10^{5}$ & {$[17]$} \\
SPR immunosensor & not mentioned & $1.6 \times 10^{6}$ & {$[18]$} \\
Fluorescent aptasensor & $10^{2}-10^{5}$ & $3.0 \times 10^{2}$ & {$[19]$} \\
Impedimetric aptasensor & $7.5 \times 10^{1}-7.5 \times 10^{5}$ & 25 & {$[20]$} \\
SPR aptasensor & $10^{2}-10^{7}$ & 60 & {$[21]$} \\
Our method & $8.4 \times 10^{3}-8.4 \times 10^{7}$ & $1.7 \times 10^{3}$ & this work \\
\end{tabular}

The original article was corrected.

The online version of the original article can be found at doi: http://dx.doi. org/10.1007/s00604-017-2241-0

Wenchao Dou

wdou@zjsu.edu.cn

Food Safety Key Laboratory of Zhejiang Province, School of Food Science and Biotechnology, Zhejiang Gongshang University,

Hangzhou 310018, China 